\title{
Effect of heat treatment on the morphology of carbon fibers doped with $\mathrm{Co}_{2} \mathrm{p}$ nanoparticles
}

\author{
M. Stelmakova ${ }^{1,2} \cdot$ M. Streckova ${ }^{1}$ D $\cdot$ R. Orinakova ${ }^{3} \cdot$ A. Guboova ${ }^{3} \cdot$ M. Balaz ${ }^{4} \cdot$ V. Girman ${ }^{1,2} \cdot$ E. Mudra ${ }^{1} \cdot$ C. Bera ${ }^{1} \cdot$ \\ M. Batkova ${ }^{5}$
}

Received: 30 April 2021 / Accepted: 22 September 2021 / Published online: 7 October 2021

(C) Institute of Chemistry, Slovak Academy of Sciences 2021

\begin{abstract}
Carbon fibers ( $\mathrm{CFs}$ ) decorated by $\mathrm{Co}_{2} \mathrm{P}$ nanoparticles and carbon nanotubes were prepared via needle-less electrospinning technique. Formation of catalytically active $\mathrm{Co}_{2} \mathrm{P}$ nanoparticles and growth of carbon nanotubes were monitored in open and closed sintering environment at different sintering exposure times. Higher porosity, important in the catalytic reaction for easier penetration of electrolyte into the CFs, was achieved by mixing two immiscible polymers with natrium dodecyl sulfate and subsequent heat treatment process. Structure and morphology of the prepared modified carbon fibers were characterized by XRD, SEM and TEM. The time of heat exposure at the sintering temperature of $1200{ }^{\circ} \mathrm{C}$ and closure of the sintering space showed distinct effect on the growth and shape of carbon nanotubes. SEM and Raman spectroscopy revealed that closure of the system led to the formation of carbon nanotubes with smaller diameters and less structural disorder. Comparing of as-prepared $\mathrm{CFs}$ revealed that $\mathrm{CFs}$ with $\mathrm{Co}_{2} \mathrm{P}$ sintered in the closed system exhibited the best electrocatalytic activity for hydrogen evolution reaction due to lower overpotential and smaller Tafel slope in acidic solution.
\end{abstract}

M. Streckova

mstreckova@saske.sk

1 Institute of Materials Research, Slovak Academy

of Sciences, Watsonova 47, 04001 Kosice, Slovak Republic

2 Institute of Physics, Faculty of Science,

P.J. Safarik University, Park Angelinum 9, 04154 Kosice, Slovak Republic

3 Institute of Chemistry, Faculty of Science, P.J. Safarik University, Moyzesova 11, 04001 Kosice, Slovak Republic

4 Institute of Geotechnics, Slovak Academy of Sciences, Watsonova 45, 04001 Kosice, Slovak Republic

5 Institute of Experimental Physics, Slovak Academy of Sciences, Watsonova 47, 04001 Kosice, Slovak Republic 


\section{Graphic abstract}

\section{Effect of heat treatment on the morphology of carbon fibers doped with $\mathrm{CO}_{2} \mathrm{P}$ nanoparticles}
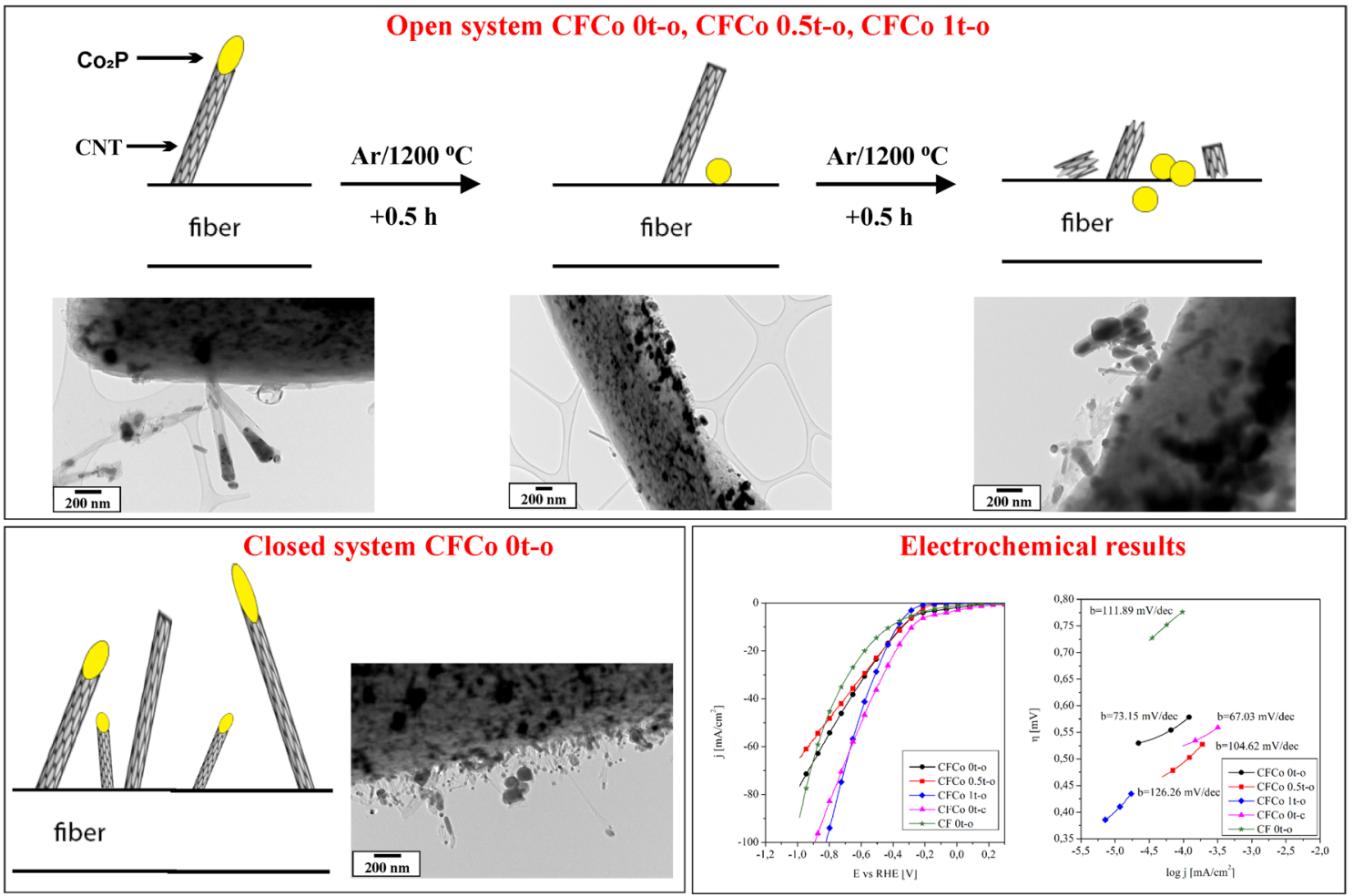

Keywords Carbon fibers $\cdot$ Cobalt phosphide $\cdot$ Heat treatment $\cdot$ HER

\section{Introduction}

The high costs of coal and gas, together with negative impact of fossil fuels on the environment and human life, have led to increased interest in the use of renewable energy. Moreover, according to the "Global Energy Review" published in April 2020 by the International Energy Agency, as one of many global world`s associations for shaping, secure and sustainable energy for future, in the, renewable energy has so far been the energy source most resilient to Covid-19 lockdown measures. According to this review, which examines the impact of the Covid-19 crisis on overall energy demand and $\mathrm{CO}_{2}$ emissions, global use of renewable energy in all sectors increased in the first quarter of 2020 by about $1.5 \%$ relative to the same quarter of 2019 (emissions 2020). Despite supply chain disruptions that have paused or delayed activity in many regions, the expansion of solar, wind and hydropower was expected to help renewable electricity generation to rise by nearly $5 \%$ in 2020 (emissions 2020). Unfortunately, fossil fuels still cover almost $60 \%$ of global electricity supply, so water, wind and solar energy as alternative energy sources present new challenges in the field of safety of energy supply, independent distribution, production, storage and use of surplus energy (Liserre et al. 2010; Stigka et al. 2014). Although renewable energy is often seen as a new technology, the use of natural power has long been used for heating, transportation, lighting and more.

Hydrogen is considered a suitable energy carrier for the future due to its high energy density, high incidence and positive impact on the environment in terms of greenhouse gas emissions (Streckova et al. 2020). Water is an abundant source of hydrogen, and therefore, much effort is aimed at extracting hydrogen from water. Electrolysis of water using a direct current derived from sustainable energy is highly eco-friendly method for production of hydrogen, as it uses renewable $\mathrm{H}_{2} \mathrm{O}$ and produces only pure oxygen as a by-product. Unfortunately, due to economic issues, only $4 \%$ of hydrogen can be currently obtained by electrolysis of water. However, water electrolysis supported by alternative energy sources (e.g., solar energy) and alternative use of other catalysts instead of noble metals could be even more economically advantageous at present. According to the experimentally measured electrochemical parameters of HER (exchange current density, overpotential, electron 
transfer kinetics, etc.) and DFT (density functional theory) calculated from the Gibbs free energy $\Delta \mathrm{G}_{\mathrm{H}}$ of the adsorbed atomic hydrogen, three most perspective alternatives for catalysts are: metals and alloys, transition metal compounds, and carbonaceous compounds (Nørskov et al. 2005; Greeley and Nørskov 2005; Wang and Johnson 2009; Zhang et al. 2018; Andrews and Citra 2002; Zeng and Li 2015; Kibsgaard et al. 2015).

Distinctive properties of carbon materials, such as wide operating potential, large variability of modifications by shaping or easy incorporation into other materials, low cost and inertness against most electrolytes, make them suitable catalysts for HER. However, amorphous carbon is an electroactive inert and possesses poor catalytic activity (Streckova et al. 2020). Therefore, it is necessary to supplement other catalysts into the carbonaceous materials that increase their electrocatalytic activity. Alternatively, one may design more suitable carbon structures such as carbon fibers (CFs), carbon nanotubes (CNTs) single-walled CNTs (SWCNTs), graphene, or glassy paper. It is known that the incorporation of transition metal nanoparticles (TMN), such as $\mathrm{Co}, \mathrm{Cu}$, $\mathrm{Ni}, \mathrm{Fe}$, significantly increases the electrocatalytic activity, the efficiency of catalysts (Zhou et al. 2016; Shi and Zhang 2016; Kong et al. 2013), and also initiates the growth of carbon nanotubes (CNTs) (Streckova et al. 2020). Carbon with tubular nanostructures such as CNTs and SWNTs has attracted considerable attention not only because of its fascinating, unique physicochemical properties, but also due to its promising applications in transistors (Bachtold et al. 2001), field-emission tips (Iijima 1991), sensors (Zhu et al. 2002), supercapacitors (An et al. 2001), and bio-medical fields (Zanello et al. 2006). Various established methods are used to prepare carbon fibers and CNTs, such as electric-arc discharge, laser ablation synthesis techniques and catalytic pyrolysis of carbon-containing gases via catalytic chemical vapor deposition (CCVD) (Hernadi et al. 2000; Lyu et al. 2004; Bonard et al. 2002; Wei et al. 2003).

Needle electrostatic spinning (NLE) is the most suitable method for production of fibers from polymer solutions (Jirsak and Petrik 2012). The principle of electrospinning is based on the generation of free charges on the surface of a polymer solution with a high voltage potential (in tens of kV) (Garg and Bowlin 2011; Inagaki et al. 2012). A Taylor cone is formed at the end of the needle, from which fibers are formed after overcoming the surface tension and are trapped on the collecting counter electrode. By this technique, the continual fibers can be created and modified by nanoparticles directly in the spinning process. Needle-less electrospinning (NLES) or electrospinning of free liquid surfaces can simultaneously generate a number of streams from the solution surface, which increases the amount of fibers prepared by an order of magnitude, thus significantly reducing the time required to produce fibers (Niu et al. 2019).
NLES is a promising technology for mass-scale production of nanofibers. Although there are some issues with the practical application, NLES is still the first choice for industrial production of nanofibers, considering its advantages and potential for continual improvement. Thanks to close collaboration between electrospinners, chemists, designers, machinery, electricians and automation controls engineers, NLES will produce high-quality nanofibers in a well-controlled way at low cost and be beneficial to our daily life, health care and various industrial sectors (Ding et al. 2019).

According to the literature and authors' knowledge, three main factors affect the catalytic behavior of carbon fibers prepared by needle-less electrospinning: i. structure of $\mathrm{CF}$ (Heckova et al. 2020) morphology and porosity of the fibers (size and diameters of $\mathrm{CF}$, defect-less structure, distribution of incorporated nanoparticles, etc.); ii. modification of $\mathrm{CF}$ (Streckova et al. 2020)—surface or interior modification by additional nanoparticles or additives (CNT growth on the surface, type of TMN, etc.); iii. final heat treatment, which can influence the building of the carbon matrix and affect the distribution of TMN and growth of CNTs (Streckova et al. 2016).

The type and dispersion of the catalyst are key factors for the formation and controlling the growth of CNTs. Therefore, a great effort has been paid to explore the optimal catalysts to enhance reactivity and efficiency for HER. It was found that the growth and structure of CNTs was greatly influenced by the form and occurrence of Co in the substrate structure (Xiang et al. 2009). The role of cobalt catalyst in the Co-MCM-41 material at different pretreatment stages of the SWCNT synthesis was investigated by Chen et al. (Chen et al. 2004a, 2004b, 2006). During the SWCNT growth process, cobalt in Co-MCM-41 substrate becomes more active after partial reduction by hydrogen prior to $\mathrm{CO}$ exposure. A narrow distribution of SWNT diameter can be achieved by optimized prereduction $\left(500-600{ }^{\circ} \mathrm{C}\right)$ and reaction temperature $\left(750-800{ }^{\circ} \mathrm{C}\right)$ and by control of cobalt cluster sizes (Chen et al. 2004a). The experimental results showed that the effect of $\mathrm{CO}$ pressure and reaction time controls synthesis of SWCNTs depending on three competitive processes: reduction in cobalt, nucleation of the reduced cobalt atoms into clusters, and initiation and growth of the carbon nanotubes (Chen et al. 2004b). The concentration and size of Co nanoparticles also affected the growth of SWCNTs. The uniform SWCNT diameters were achieved at a cobalt cluster size of approximately $6-8 \AA$ with concentration of Co catalytic nanoparticles of 3 wt.\% (Chen et al. 2006).

In this article, the main goal is the investigation of the effect of heat treatment on the morphology and electrocatalytic activity of CFs modified by cobalt phosphide nanoparticles $\left(\mathrm{CoP}, \mathrm{Co}_{2} \mathrm{P}\right)$ for HER. Polymeric fibers containing the source compounds for $\mathrm{Co}_{2} \mathrm{P}$ nanoparticles formation have been produced by NLES. These compounds are represented 
Table 1 Composition and exposure times at $1200^{\circ} \mathrm{C}$ for the precursor fiber solutions

\begin{tabular}{llllllll}
\hline Sample & DMF $[\mathrm{ml}]$ & $\mathrm{PAN}[\mathrm{g}]$ & $\mathrm{PVP}[\mathrm{g}]$ & $\mathrm{H}_{3} \mathrm{PO}_{4}[\mu \mathrm{l}]$ & $\mathrm{SDS}[\mathrm{g}]$ & $\mathrm{Co}\left(\mathrm{NO}_{3}\right)_{2}[\mathrm{~g}]$ & $\begin{array}{l}\text { exposure } \\
\text { time }[\mathrm{h}]\end{array}$ \\
\hline CF 0t-0 & 10 & 1 & 1 & 100 & 0.3 & 0 & 0 \\
CF 0t-c & 10 & 1 & 1 & 100 & 0.3 & 0 & 0 \\
CFCo 0t-o & 10 & 1 & 1 & 100 & 0.3 & 1 & 0 \\
CFCo 0t-c & 10 & 1 & 1 & 100 & 0.3 & 1 & 0 \\
CFCo 0.5t-0 & 10 & 1 & 1 & 100 & 0.3 & 1 & 0.5 \\
CFCo 0.5t-c & 10 & 1 & 1 & 100 & 0.3 & 1 & 0.5 \\
CFCo 1t-o & 10 & 1 & 1 & 100 & 0.3 & 1 & 1 \\
\hline
\end{tabular}

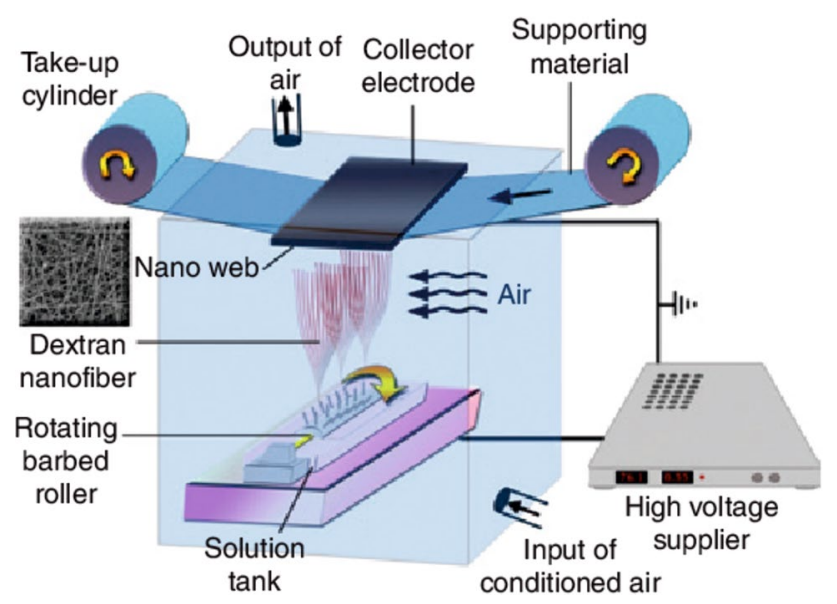

Fig. 1 Schematic diagram of the needle-less electrospinning system (Yalcinkaya et al. 2016)

by cobalt nitride and phosphoric acid. The further main step of modified carbon fibers preparation is sintering at 1200 ${ }^{\circ} \mathrm{C}$ in $\mathrm{Ar}$ atmosphere. The heat treatment process is responsible for carbon ladder matrix formation with incorporated $\mathrm{Co}_{2} \mathrm{P}$ nanoparticles (Streckova et al. 2018). Cobalt phosphate nanoparticles have been incorporated into the carbon matrix in situ in the heat treatment process and act as the catalysts for CNT growth during sintering. The growth of CNT was performed according to the "Tip growth model" (Streckova et al. 2020).

No additional surface modification was necessary. The used sintering conditions had a great influence on the morphology, porosity and growth of CNTs on the CF surface, which had a positive effect on the active surface area for HER. CNT growth was catalyzed by the presence of CoP nanoparticles. Fiber morphology and CNT growth were observed by SEM and TEM. The type of phosphides was determined by XRD, and the amount of Co in the fibers was determined by atomic absorption spectroscopy (AAS). The electrocatalytic activity of fibers and the effect on hydrogen evolution were analyzed using linear sweep voltammetry and Tafel slopes. The turnover frequencies (TOF) were calculated to further assess the electrocatalytic activity of two most active samples.

\section{Experimental}

\section{Materials}

The solutions used to prepare the precursor fibers were composed of two polymers: polyacrylonitrile (PAN, $\mathrm{Mw}=150000 \mathrm{~g} \cdot \mathrm{mol}^{-1}$, Sigma-Aldrich) and polyvinylpyrrolidone (PVP, $\mathrm{Mw}=55000 \mathrm{~g} \cdot \mathrm{mol}^{-1}$, Sigma-Aldrich). Phosphoric acid $\left(\mathrm{H}_{3} \mathrm{PO}_{4}\right.$, Merck, $\left.85 \%\right)$ was employed to enhance the viscosity and conductivity and hence, the spinnability of the precursor solution. Sodium dodecyl sulfate (SDS, Merck, $90 \%$ ) was used as a surfactant to improve porosity. N,Ndimethylformamide (DMF, Acros Organic, 99.8\%) was used as a solvent. Cobalt nitrate hexahydrate $\left[\mathrm{Co}\left(\mathrm{NO}_{3}\right)_{2} \cdot 6 \mathrm{H}_{2} \mathrm{O}\right.$, Sigma-Aldrich, p.a.] was added as a source of Co nanoparticles. Electrochemical measurements were performed in $0.5 \mathrm{M}$ sulfuric acid $\left(\mathrm{H}_{2} \mathrm{SO}_{4}\right.$, Centralchem, $\left.96 \%\right)$.

\section{Methods}

\section{Fibers preparation}

Precursor solutions were prepared by dissolving PAN, PVP, SDS and $\mathrm{Co}\left(\mathrm{NO}_{3}\right)_{2}$ in DMF for two hours at $80{ }^{\circ} \mathrm{C}$. Then, $\mathrm{H}_{3} \mathrm{PO}_{4}$ was added dropwise, and the solutions were stirred vigorously for another $1 \mathrm{~h}$ at $90{ }^{\circ} \mathrm{C}$ until homogenization was complete. The notation of the as-prepared CF samples with the composition of the precursor polymer solutions and the sintering exposure times at $1200^{\circ} \mathrm{C}$ is given in Table 1

Carbon fibers (CFs) were prepared by needle-less electrospinning (NLES) using Nanospider ${ }^{\mathrm{TM}}$ NS LAB (Elmarco, Czech Republic) from precursor solutions. The precursor solutions were poured into a spinning bath $(30 \mathrm{ml}$ vessel and a rotating electrode), and the spinning distance between the electrodes was kept at $180-190 \mathrm{~mm}$. The rotation speed 
of the spinning electrode was adjusted to $8 \mathrm{rpm}$, and a high voltage of $50-60 \mathrm{kV}$ was applied to the surface of the spinning drum. A schematic diagram of the needle-less electrospinning system is depicted in Fig. 1 (Yalcinkaya et al. 2016).

The heat treatment optimization of PAN-based fibers is the key factor, especially in such composite systems as modified CFs with cobalt phosphide nanoparticles (Rahaman et al. 2007). The sintering of the CFs was carried out at 1200 ${ }^{\circ} \mathrm{C}$ in Ar atmosphere in an open system (referred to as -o), which means free access of Ar into the sample with the possibility of releasing gases to the environment. Another way was sintering in a closed system (referred to as -c) where the gases originated during sintering process $\left(\mathrm{H}_{2}, \mathrm{CO}_{2}, \mathrm{CO}\right.$ and Ar) stayed in the system and were prevented from escaping. The sintering time at the maximum temperature is referred to as "-t" (e.g., -0t means no exposure time, -1t means $1 \mathrm{~h}$ ). The complete notation of the samples sintered in a closed and open system is summarized in (Table 1).

\section{Fibers characterization}

Structural characterization of the prepared fibrous samples was done by XRD analysis (PhilipsX' PertPro, CuK $\alpha$

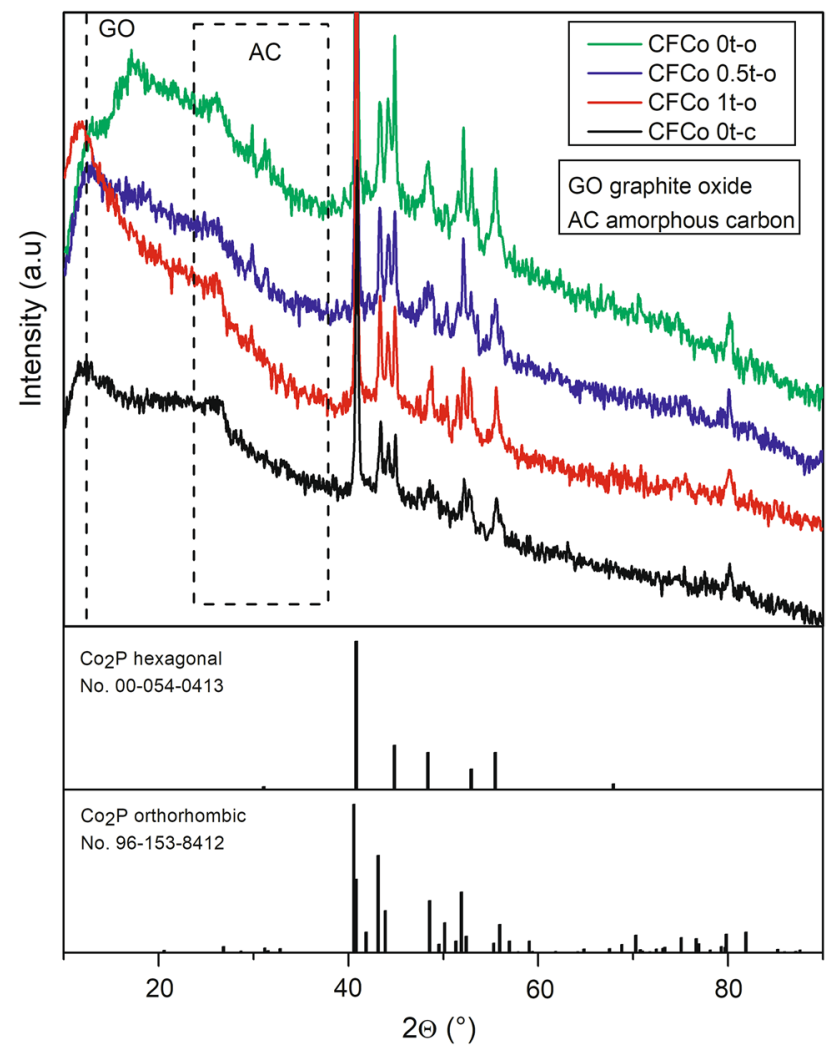

Fig. 2 XRD diffraction pattern for CFCo 0t-o, CFCo 0.5t-o, CFCo $1 \mathrm{t}-\mathrm{o}, \mathrm{CFCo} 0 \mathrm{t}-\mathrm{c}$ radiation). The morphology, size and shape of modified CFs were visualized by scanning electron microscope (SEM, JSM-7000F, JEOL, Japan) and transmission electron microscope (TEM, JEM-2100F, JEOL, Japan). Active surface area for HER was determined from adsorption/desorption isotherms using the NOVA 1200e Surface Area \& Pore Size Analyzer (Quantachrome Instruments, USA). The values of specific surface area $\left(\mathrm{S}_{\mathrm{BET}}\right)$ were determined by ethe Brunauer-Emmett-Teller method $\left(S_{t}\right)$. Atomic absorption spectroscopy (AAS, Atomic Absorption Spectrometer PerkinElmer) was used to determine the cobalt content in the fibers. The Raman spectra were measured by the Raman spectroscopy (HORIBA -BX41TF).

The electrocatalytic HER performance was evaluated by linear sweep voltammetry (LSV) method in a three-electrode cell configuration connected to the Autolab potentiostat (PGSTAT302N, Metrohm, Switzerland) at ambient conditions. LSV measurements were performed in $0.5 \mathrm{M} \mathrm{H}_{2} \mathrm{SO}_{4}$ aqueous solution at a scan rate of $1 \mathrm{mVs}^{-1}$ in the potential range from $+600 \mathrm{mV}$ to $-1200 \mathrm{mV}$ (vs. $\mathrm{Ag} / \mathrm{AgCl} / 3 \mathrm{M} \mathrm{KCl}$ ). A silver chloride electrode $(\mathrm{Ag} / \mathrm{AgCl} / 3 \mathrm{M} \mathrm{KCl})$ and a large area platinum foil were used as the reference and the counter electrode, respectively. All potentials were calibrated to a reversible hydrogen electrode (RHE). The carbon fibers in the form of carbon foam, used as compact electrode for electrochemical measurement, were weighted and directly used as working electrodes without further modification. All polarization curves were measured without IR correction.

\section{Results}

\section{XRD characterization}

The phase structure and crystallinity of carbon fibers modified by cobalt phosphides CFCo 0t-o, CFCo 0.5t-o, CFCo 1t-o, CFCo 0t-c with different heat treatment conditions were first identified by XRD. The obtained XRD pattern is shown in Fig. 2. Two different structures of cobalt phosphide were present in all forms of CFs. Two types of $\mathrm{Co}_{2} \mathrm{P}$ nanoparticles were observed: i. hexagonal, characterized by diffraction peaks $\sim 2 \Theta=40.836^{\circ}, 44.856^{\circ}, 48.376^{\circ}, 52.946^{\circ}, 55.477^{\circ}$ and indexed to (111), (021), (120), (002), (030) planes, and ii. orthorhombic, with diffraction peaks at $\sim 2 \Theta=40.573^{\circ}$, $40.837^{\circ}, 43.144^{\circ}, 43.888^{\circ}, 48.560^{\circ}, 50.145^{\circ}, 51.911^{\circ}$, $79.808^{\circ}, 81.889^{\circ}$ indexed as (112), (210), (211), (103), (013), (301), (020), (322), (314) planes,. The characteristic diffraction of graphite/graphene oxide (GO) peak at $\sim 2 \Theta=12.4^{\circ}$ corresponding to the oxidation of the carbon structure and the formation of an oxygenated functional groups was identified (Johra et al. 2017; Kartick et al. 2013). Increasing GO peak intensity was detected with increasing exposure time at high temperature (the order, starting from 

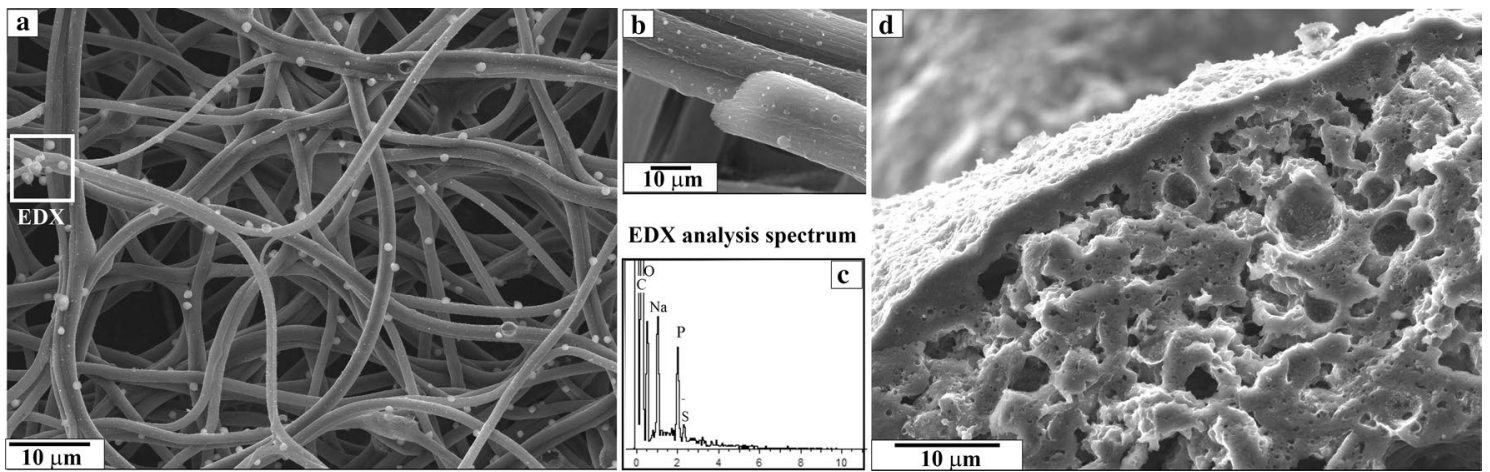

Fig. 3 SEM image of bare CFs, thermally treated in Ar atmosphere at $1200{ }^{\circ} \mathrm{C}$ : (a) fibrous structure of the CF 0t-o sintered in an open system, (b) detail of the morphology of CF 0t-o, (c) EDX analysis of CF 0t-o, (d) deteriorated structure of CF 0t-c sintered in a closed system

the lowest intensity, was CFCo 0t-o, CFCo 0.5t-o and CFCo 1t-o). Similarly, GO peak intensity decreased in the closed system CFCo 0t-c, where the presence of released hydrogen led to suppression of oxidation reactions. The small peak at $\sim 2 \Theta=24.3^{\circ}$ with the additional broadening at the bottom of the peaks around $\sim 2 \Theta=43.2^{\circ}$ can be identified as amorphous carbon $(\mathrm{AC})$ in all observed samples. Generally, the broadening around the peak $2 \Theta \approx 20^{\circ}$ in XRD diffraction pattern can be assigned to the amorphous carbon what is typical for carbonaceous materials.

\section{Morphological characterization}

\section{Bare carbon fibers}

Bare carbon fibers were prepared from a mixture of PAN and PVP polymers in combination with SDS as a surfactant according to Table 1 . The use of these two immiscible polymers in combination with SDS led to the creation of micelle structure (Heckova et al. 2020). Ionic surfactants play an important role in the fabrication of carbon-based fibers, because they facilitate the processability of carbon precursors and allow controlled alteration of carbon properties. It has been found that the microporosity of the electrospun carbon nanofibers is promoted in the presence of anionic sodium dodecyl sulfate (SDS) surfactant, regardless of whether metal particles are presented or not (Aykut et al. 2016). According to our previous studies (Heckova et al. 2020), heat treatment and extraction of the micelles from the porous structure of PAN matrix is suitable for better penetration of the electrolyte during the HER process; therefore, the formed micelles were extracted at high carbonization temperatures.

Regarding the evolution of hydrogen during the polymer ladder building, two different ways of the carbonization process were studied. The first was the sintering process in an open system (CF 0t-o), where the precursor fibers were loosely carbonized and all by-products could evolve into the environment. The second one was realized in a closed system (CF 0t-c), where the fibers were carbonized in closed crucibles to prevent the release of hydrogen from the system, which also prevented the surface of the fibers being disturbed and thus, the porosity was increased. A comparison of the morphological characteristics of the two pure carbon fibers CF 0t-o and CF 0t-c calcined in an Ar atmosphere at $1200{ }^{\circ} \mathrm{C}$ is shown in the SEM images in Fig. 3. The continuous fibrous structure was observed for CF 0t-o sample with a diameter of 1.2 to $2.5 \mu \mathrm{m}$ with a fine wrinkled surface (Fig. 3a,b). A lot of small spherical particles were dispersed outside and inside the carbon fibers, which were identified by EDX analysis as sodium phosphate particles created after the heat treatment process (Fig. 3c). Figure $3 \mathrm{~d}$ shows the structure of the sample sintered in the closed system. As evident, the accumulation of the heat and hydrogen (as a by-product of the PAN pyrolysis) in the fibrous environment led to the deterioration and collapse of the fibrous structure (Fig. 3d). The closure of the system assumed accumulation and re-spilling of hydrogen into the carbon structure, which is expected to increase the porosity. However, the effect of hydrogen in a closed system is destructive and does not produce the desired fiber properties; in the case of bare carbon fibers, this is reflected a specific surface area as low as 13.5 $\mathrm{m}^{2} / \mathrm{g}$.

\section{Carbon fibers modified by cobalt phosphide nanoparticles}

$\mathrm{Co}_{2} \mathrm{P}$ phosphides belong to the family of materials, which enhance the electrocatalysis of hydrogen from water. CNTs increase the active surface area and support the conductivity of the final material. Therefore, the prepared bare CFs were subsequently modified with both $\mathrm{Co}_{2} \mathrm{P}$ nanoparticles and CNTs. It should be noted that $\mathrm{Co}_{2} \mathrm{P}$ nanoparticles were formed in carbon fibers spontaneously at high temperature and in an inert atmosphere from polymer precursor fibers containing $\mathrm{Co}\left(\mathrm{NO}_{3}\right)_{2}$. Effect of the sintering temperature and time of exposure in the open system on the microstructure of 
Fig. 4 SEM and TEM images of carbon fibers with incorporated $\mathrm{Co}_{2} \mathrm{P}$ nanoparticles thermally treated in Ar atmosphere in open system with prolonged time of exposure at $1200{ }^{\circ} \mathrm{C}$ : (a, b) $\mathrm{CFCo} 0 \mathrm{t}-\mathrm{o}$ without exposure (c, d) CFCo 0.5t-o with exposure of $0.5 \mathrm{~h}(\mathbf{e}, \mathbf{f})$ CFCo $1 \mathrm{t}-\mathrm{o}$ with exposure of $1 \mathrm{~h}$
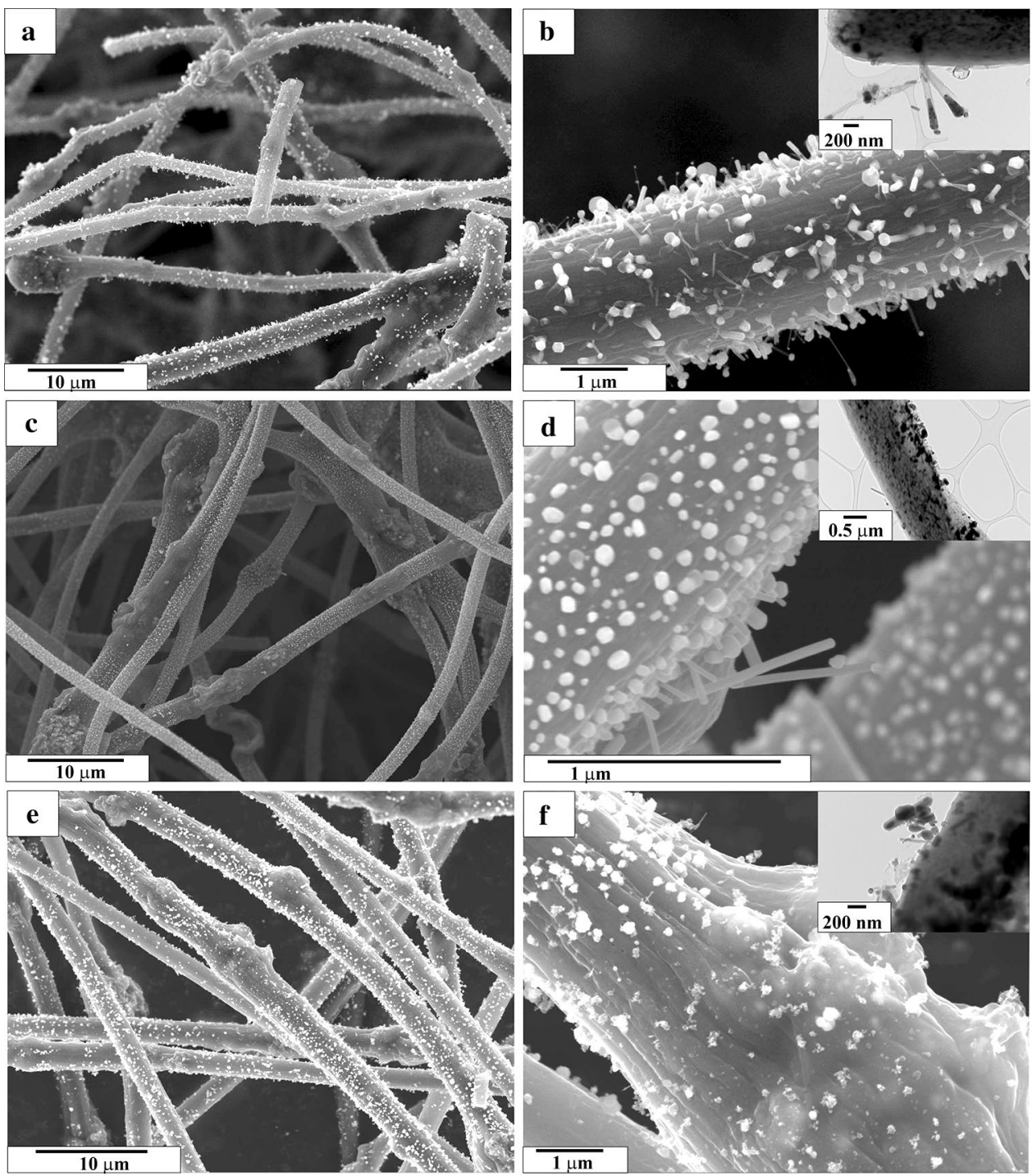

CFCo 0t-o, CFCo 0.5t-o, CFCo 1t-o samples was monitored by SEM and TEM (Fig. 4). As can be seen, the continuous fibrous structure was maintained in all cases of different exposure times. The rough and wrinkled surface with a fiber diameter of $0.8-3.9 \mu \mathrm{m}$ contained $\mathrm{Co}_{2} \mathrm{P}$ nanoparticles densely distributed outside as well as inside the carbon fiber matrix (Fig. 4a,c,e). SEM images at larger magnifications confirmed a homogeneous distribution of CNTs and $\mathrm{Co}_{2} \mathrm{P}$ nanoparticles (Fig. 4b,d,f). Moreover, the presence of CNTs was observed on the surface of the samples, and their growth and amount were influenced by the sintering exposure time. As shown in Fig. 4, sintering of CFs upon thermal exposure led to a reduction in the amount of CNTs and metal phosphide nanoparticles. A significant amount of CNTs was observed on the carbon surface matrix of the CFCo 0t-o sample (Fig. 4a,b). TEM proved the growth of CNTs initiated by $\mathrm{Co}_{2} \mathrm{P}$ nanoparticles (zoom in Fig. 4b). The prolonged time of exposure at high temperatures resulted in decrease
CNT growth (Fig. 4c,d). Due to the long exposure of heat treatment, the CNTs disintegrate and disappear, whereas agglomeration of $\mathrm{Co}_{2} \mathrm{P}$ occurs (Fig. $4 \mathrm{e}, \mathrm{f}$ ).

The effect of the closed sintering system on the morphology of $\mathrm{CFs}$ modified by $\mathrm{Co}_{2} \mathrm{P}$ nanoparticles was also observed (Fig. 5). By comparing of carbon fibers sintered in the open system, both samples exhibited fibrous structure, but the surface of CFCoOt-c was more wrinkled with irregular cylindrical structure and distribution of soft CNTs. TEM images confirmed the higher amount of thinner and finer CNTs (Fig. 5c). Extending the time of heat treatment at $1200{ }^{\circ} \mathrm{C}$ to $0.5 \mathrm{~h}$ led to the extinction of fine CNT fibers; therefore, it was not appropriate to further prolong the sintering time. The deteriorated fibrous structure indicated the possibility of an overall collapse of the carbon fibers as in the case of pure carbon fibers (Fig. 3). A reduced amount of carbon nanotubes with extended sintering time is indicated in Fig. 5d. 
Fig. 5 SEM and TEM images of carbon fibers with incorporated $\mathrm{Co}_{2} \mathrm{P}$ nanoparticles thermally treated in Ar atmosphere at $1200{ }^{\circ} \mathrm{C}$ in closed system: (a) CFCo 0t-c, (b) detail on CNTs of CFCo 0t-c sample (c) TEM of CFCo 0t-c, (d) TEM of CFCo 0.5t-c
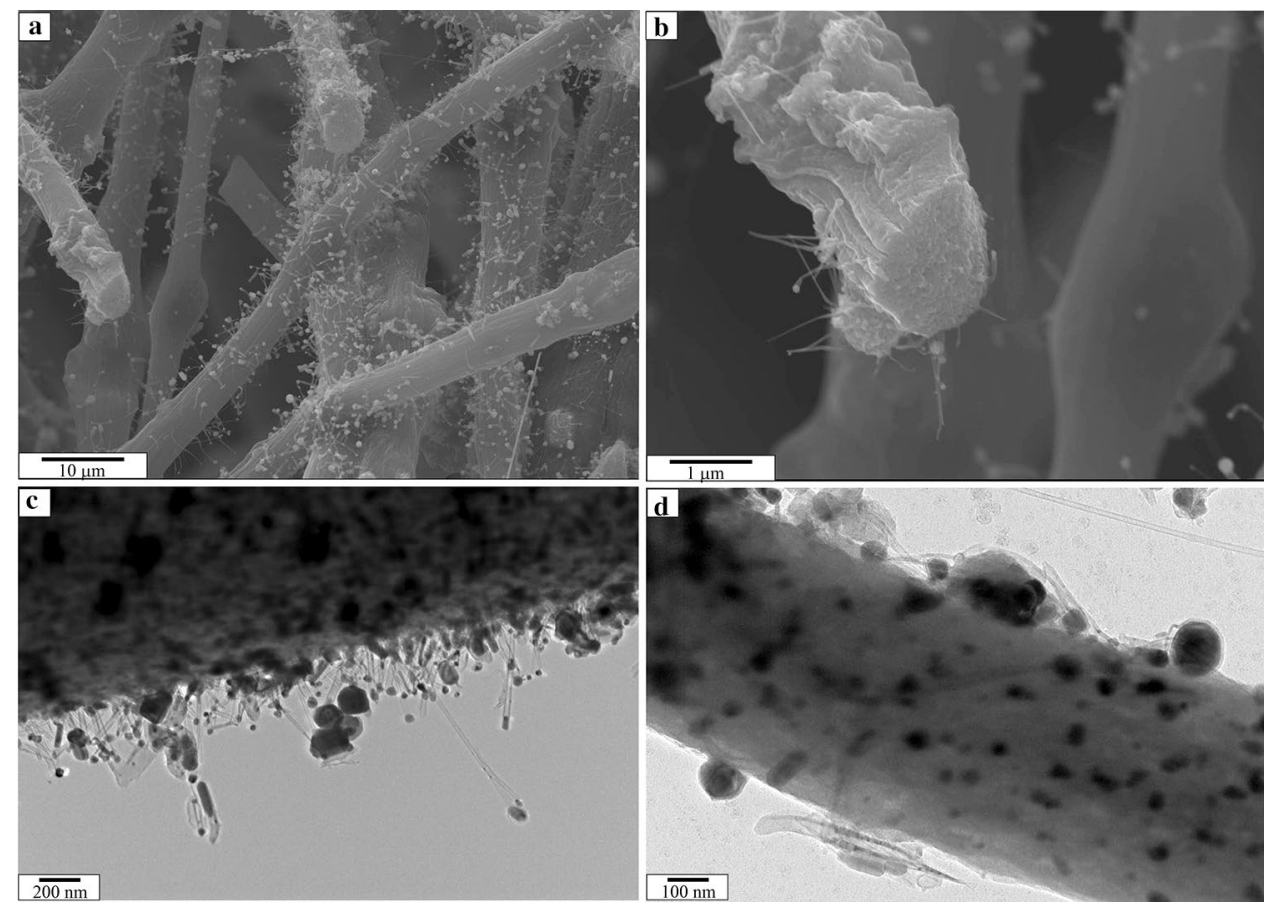

Fig. 6 a Raman Spectrum of CFCo 0t in closed and open systems, b HRTM of CFCo 0t-o: multiwalled CNT growth on the carbon matrix initiated by the $\mathrm{Co}_{2} \mathrm{P}$ nanoparticles

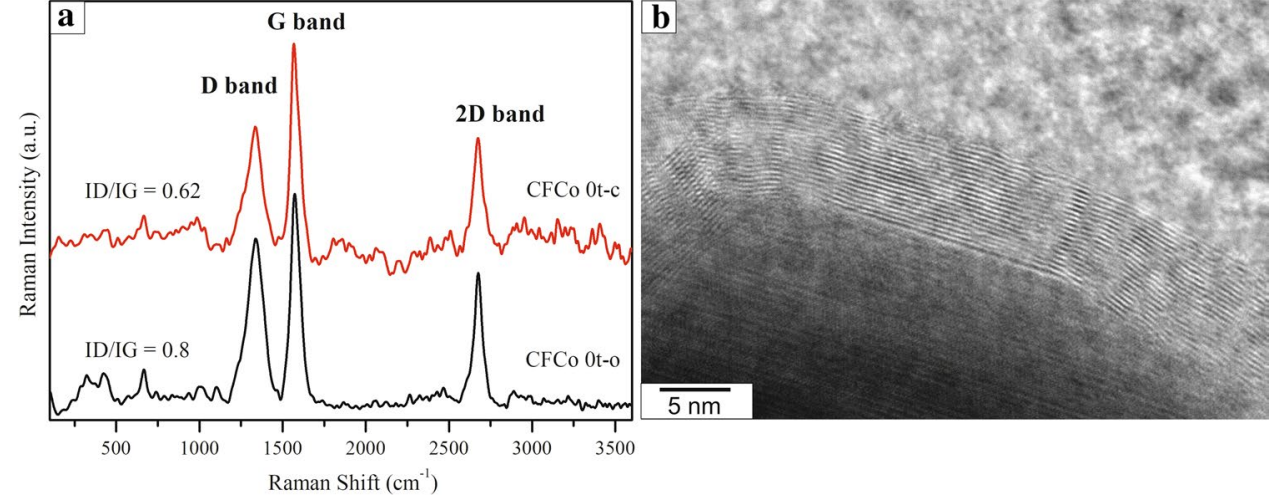

Raman Shift $\left(\mathrm{cm}^{-1}\right)$

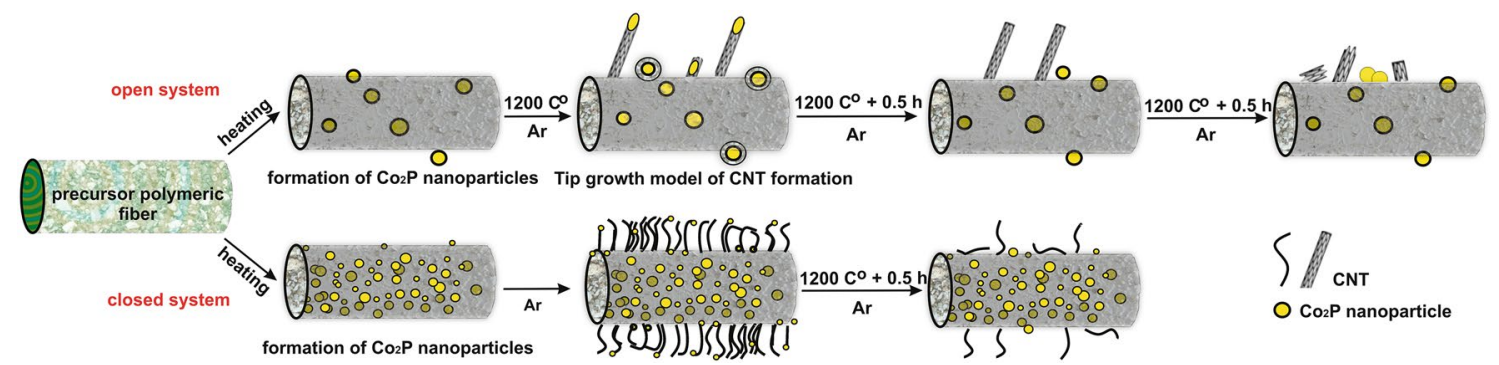

Scheme 1 Scheme of growth and subsequent degradation of CNTs due to the prolonged exposure time at $1200{ }^{\circ} \mathrm{C}$ in $\mathrm{Ar}$ atmosphere

The CNT structure in CFCo 0t-o and CFCo 0t-c was confirmed by the Raman spectra (Fig. 6a,b). Both CFCo Ot-o and CFCo 0t-c samples had D-, G- and 2D peaks characteristic of graphene-based materials, which confirms the presence of CNTs. Relatively high defect-activated Raman D peak indicates more disordered structure of CNTs. In addition, the small width of the 2D peak indicates the multilayer configuration of Co-initiated CNTs, as confirmed by 
EDX mapping analysis of $\mathrm{Co} 2 \mathrm{P}$ nanopraticles
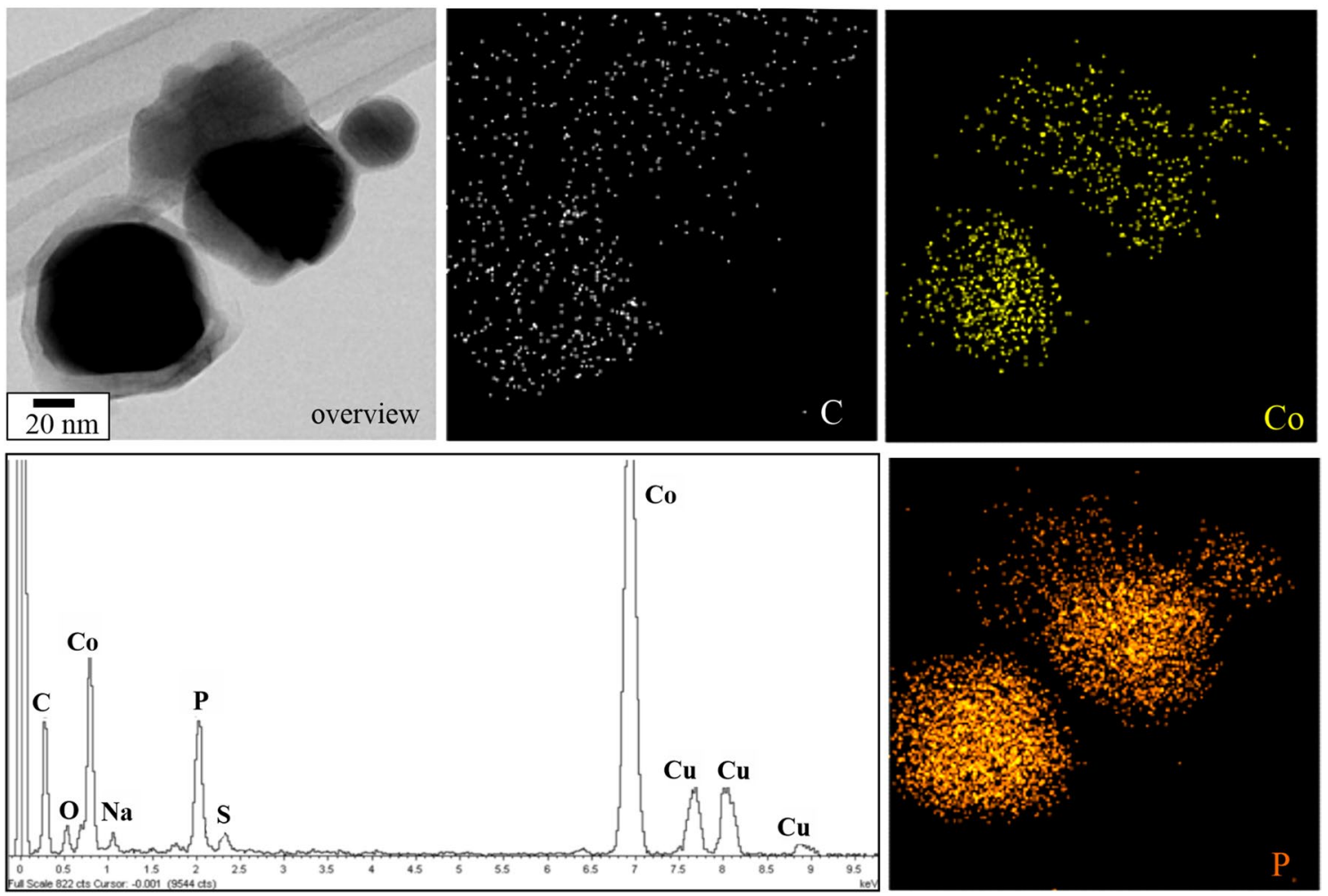

Fig. 7 Elemental mapping and EDX analysis of $\mathrm{Co}_{2} \mathrm{P}$ nanoparticles

Table 2 Values of electrocatalytic activity parameters of carbon fibers with $\mathrm{Co}_{2} \mathrm{P}$ nanoparticles for HER at different heat treatment conditions

\begin{tabular}{llllllllll}
\hline Sample & $\mathrm{m}[\mathrm{mg}]$ & $\mathrm{S}_{\mathrm{BET}}\left[\mathrm{m}^{2} / \mathrm{g}\right]$ & $\mathrm{S}_{\mathrm{t}}\left[\mathrm{m}^{2} / \mathrm{g}\right]$ & $\mathrm{E}_{\text {onset }}[\mathrm{mV}]$ & $\eta_{10}[\mathrm{mV}]$ & $\eta_{20}[\mathrm{mV}]$ & $B[\mathrm{mV} / \mathrm{dec}]$ & $j_{0}\left[\mathrm{~mA} / \mathrm{cm}^{2}\right]$ & $\mathrm{Metal} \mathrm{content} \mathrm{\%}$ \\
\hline CFCo 0t-o & 4.1 & 349.6 & 57.75 & -218.66 & -345.07 & -479.56 & 73.15 & 2.219 & 11.6 \\
CFCo 0.5t-o & 4.4 & 273.2 & 93.27 & -226.81 & -339.11 & -482.45 & 107.62 & 0.268 & 13.1 \\
CFCo 1t-o & 4.1 & 55 & $/$ & -288.64 & -372.67 & -450.83 & 126.26 & 0.48 & 14.0 \\
CFCo 0t-c & 4.9 & 122.5 & 43.73 & -157.16 & -280.86 & -380.99 & 67.03 & 1.754 & 9.67 \\
CF 0t-o & 9.1 & 13.5 & $/$ & -443.79 & -421.80 & -578.49 & 111.89 & 0.126 & 0 \\
\hline
\end{tabular}

HRTEM (Fig. 6b). The D to G peak intensity ratio (ID/IG) is often employed to evaluate the level of disorder in CNTs. The lower ID/IG value (0.62) for the CFCo 0t-c sample indicates that the closure of the system led to a more ordered structure with higher amount of thinner CNTs. The mechanism of CNTs growth has been previously discussed by many other authors; however, the upraise of CNTs in situ by affecting temperature is very rare (Kumar and Ando 2010; Pérez-Cabero et al. 2004; Zhao et al. 2006; Yuan et al. 2003; Mo et al. 2001; Vinciguerra et al. 2003). As mentioned in the authors' previous work, $\mathrm{Co}$ and $\mathrm{Co}_{2} \mathrm{P}$ nanoparticles can initiate the growth of CNTs as described in the "tip growth model" (Streckova et al. 2020). The suggested mechanism of growth and deterioration of carbon nanotubes affected by the prolongation of exposure times at $1200{ }^{\circ} \mathrm{C}$ is depicted in Scheme 1. First, the high temperature causes the growth of CNTs that has been catalyzed by $\mathrm{Co}_{2} \mathrm{P}$ nanoparticles immersed on the surface of CFs. The prolonged exposure time causes the falling out of $\mathrm{Co}_{2} \mathrm{P}$ nanoparticles and degradation of carbon nanotubes. Finally, long exposure at the high temperature leads to the aggregation of $\mathrm{Co}_{2} \mathrm{P}$ nanoparticles on the surface of carbon matrix and the subsequent penetration of $\mathrm{Co}_{2} \mathrm{P}$ nanoparticles into the interior of the fibers. The collapse of CNTs is evident.

The chemical composition of $\mathrm{Co}_{2} \mathrm{P}$ nanoparticles encapsulated in the carbon matrix was proved by the EDX mapping analysis shown in Fig. 7. It is evident that the 


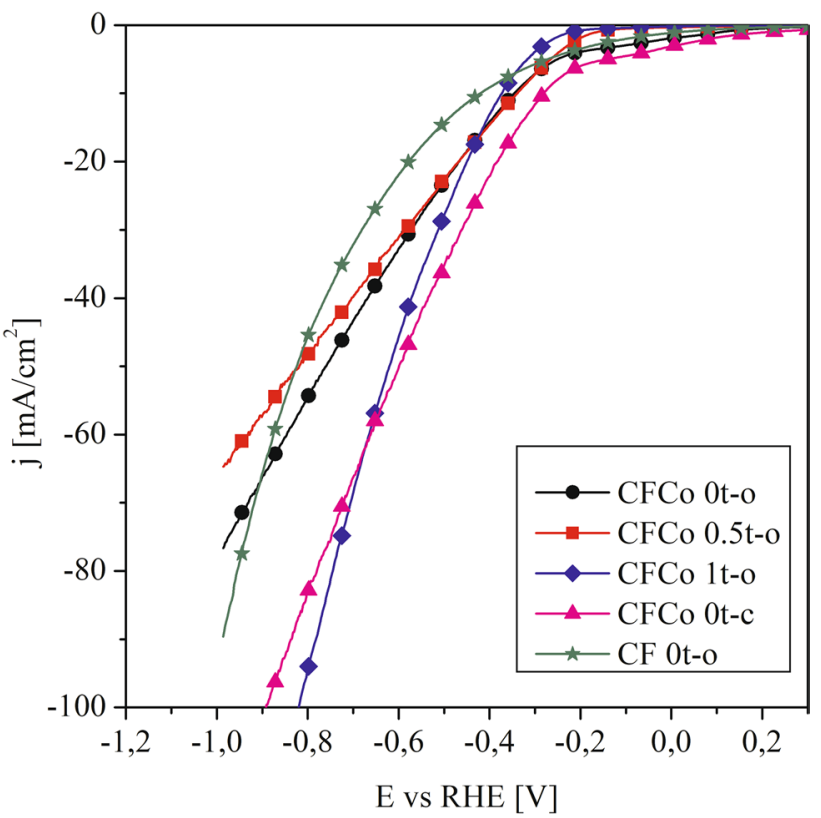

Fig. 8 LSV curves of $\mathrm{CF}$ with/without $\mathrm{Co}_{2} \mathrm{P}$ nanoparticles thermally treated in $\mathrm{Ar}$ atmosphere at different exposure times

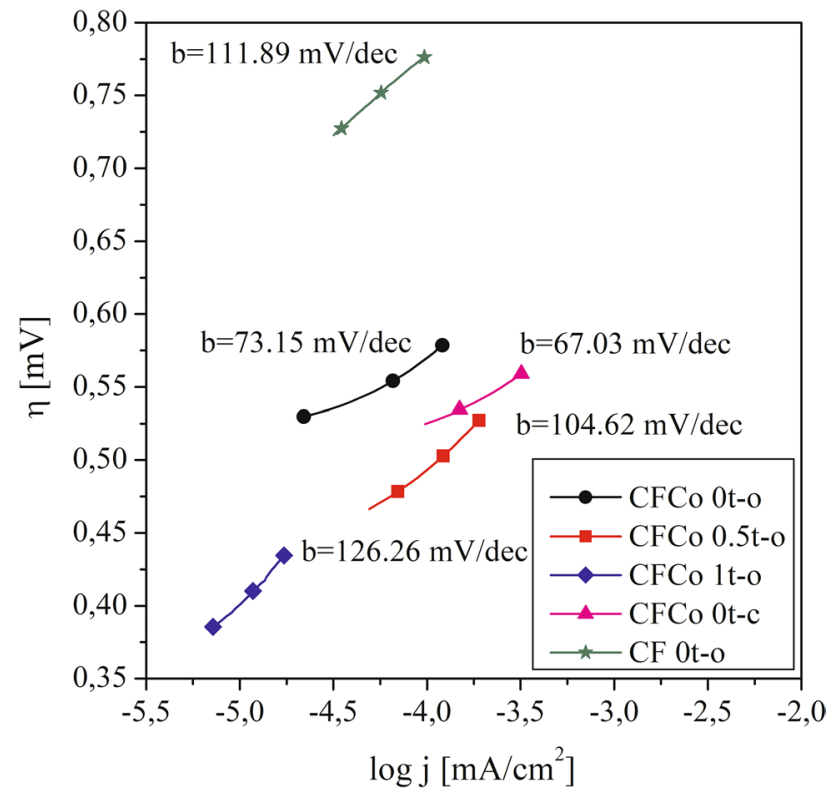

Fig. 9 Tafel slopes with/without $\mathrm{Co}_{2} \mathrm{P}$ nanoparticles thermally treated in $\mathrm{Ar}$ atmosphere at different exposure times

homogeneous distribution of $\mathrm{Co}$ and $\mathrm{P}$ elements at the same spots was confirmed.

\section{Electrochemical characterization}

The HER activity measurements were carried out in an acidic medium of 0.5 mol. $\mathrm{dm}^{-3} \mathrm{H}_{2} \mathrm{SO}_{4}$ using a

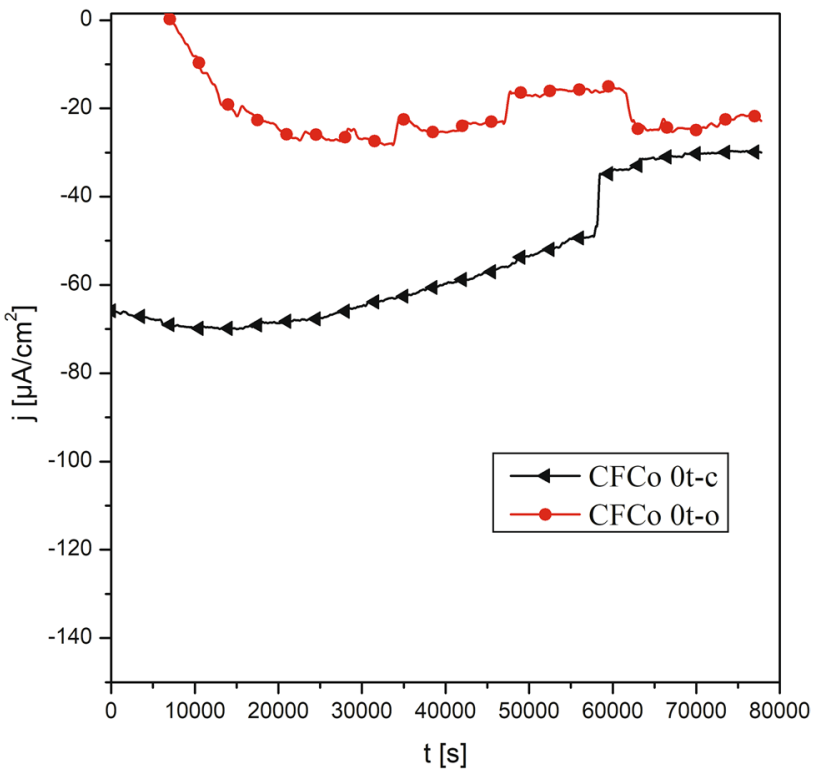

Fig. 10 Plots of current density vs. time held at a constant overpotential of $200 \mathrm{mV}$ for $80,000 \mathrm{~s}$ for the two most efficient samples: CFCo 0t-c and CFCo 0t-o

three-electrode system. The electrocatalytic activity of carbon fibers was evaluated electrochemically on a compact fibrous sample. The fibers were not affected in any way prior to measurements to preserve the porosity, structure of CNTs and active sites for HER. The structure of fibers was maintained during the measurements. The HER activity of all studied fibrous samples was derived from the values of electrocatalytic activity parameters, such as onset potential $\left(\mathrm{E}_{\text {onset }}\right)$, overpotentials to achieve cathodic current density of $10 \mathrm{mAcm}^{-2}(\eta 10)$ and $20 \mathrm{mAcm}^{-2}(\eta 20)$, exchange current density $\left(j_{0}\right)$ and Tafel slope $(b)$ calculated from LSV curves. The data are summarized in Table 2. As can be seen in Fig. 8., the polarization curves revealed that the catalyst CFCo 0t-c produced in the closed sintering system without exposure exhibits the highest HER activity with the overpotential of $-280.86 \mathrm{mV}$ at the cathodic current density of $10 \mathrm{~mA} \cdot \mathrm{cm}^{-2}\left(\eta_{10}\right)$ and $-380.99 \mathrm{mV}$ at the cathodic current density of $20 \mathrm{~mA} . \mathrm{cm}^{-2}\left(\eta_{20}\right)$ (Fig. 8). In contrast, catalysts prepared in the open system exhibit higher overpotentials with prolonged time of exposure at high temperatures. The worse HER performance of the samples sintered in the open system at longer exposure times could be associated with agglomeration of $\mathrm{Co}_{2} \mathrm{P}$ nanoparticles and degradation of CNTs, resulting in lower active surface area (only55 m/2 $/ \mathrm{g}$ for the CFCo 1t-o sample). The catalyst without active cobalt phosphide nanoparticles CF 0t-o exhibits the lowest electrocatalytic activity among all studied samples, which is in good agreement with previous studies (Streckova et al. 2020). The poor HER activity of bare CFs indicates that incorporation of $\mathrm{Co}_{2} \mathrm{P}$ nanoparticles into samples 
significantly enhances the catalytic activity, which may be related to the fact that the $\mathrm{Co}_{2} \mathrm{P}$ nanoparticles present in the fibers not only catalyze HER but also initiate the growth of CNTs. Tafel slopes (Fig. 9) were calculated using Tafel plots derived from the polarization curves. Smaller Tafel slope usually corresponds to a steep rise of the electrocatalytic current density and indicates a fast reaction rate. The lowest values of Tafel slopes were obtained for catalysts fabricated in the closed system without exposure at high temperature $(b=67.03$ and 73.15 for CFCo $0 t-c$ and CFCo 0t-o, respectively). This indicates that HER took place via Volmer and Heyrovsky pathway.

A long-term stability test was performed to assess the stability and durability of the best-performing CFCo fibers produced with zero time of exposure in closed and open systems (CFCo 0t-c, CFCo 0t-o). The undeniable stability of these samples can be seen from the time-dependent current density curves (Fig. 10) for a static overpotential of $200 \mathrm{mV}$ and a catalytic activity sustained for over $22 \mathrm{~h}$.

The turnover frequencies (TOF) were calculated to further assess the electrocatalytic activity of two the most active samples (CFCo 0t-o and CFCo 0t-c). TOF estimation for the HER in $0.5 \mathrm{M} \mathrm{H}_{2} \mathrm{SO}_{4}$ was performed conceding that each individual $\mathrm{Co}$ and $\mathrm{P}$ atom on the outermost surface layer is a potentially active site due to the vagueness of the hydrogen binding sites (Nørskov et al. 2005; Chen et al. 2014). Both theoretical and experimental surface areas were used for TOF calculations. Experimental surface areas were derived from $\mathrm{S}_{\mathrm{BET}}$ values, supposing that the surface area of $\mathrm{Co}_{2} \mathrm{P}$ nanoparticles represents $10 \%$ and $12 \%$ of experimentally determined surface area for CFCo 0t-o and CFCo 0t-c samples, respectively, based on the Co content (Table 2). Theoretical surface areas were calculated assuming $70 \mathrm{~nm}(\mathrm{~d})$ spherical $\mathrm{Co}_{2} \mathrm{P}$ particles. The TOF values for CFCo $0 t-c$ sample calculated utilizing the theoretical surface area are $67.77 \mathrm{~s}^{-1}$ at $\eta=100 \mathrm{mV}$ and $91.41 \mathrm{~s}^{-1}$ at $\eta=200 \mathrm{mV}$. The TOF values estimated for this sample using experimental surface area are $73.73 \mathrm{~s}^{-1}$ at $\eta=100 \mathrm{mV}$ and $99.45 \mathrm{~s}^{-1}$ at $\eta=200 \mathrm{mV}$. The TOFs obtained by both methods are in good agreement. The TOF values for CFCo 0t-o sample determined by use of the theoretical surface area are $9.46 \mathrm{~s}^{-1}$ at $\eta=100 \mathrm{mV}$ and $12.96 \mathrm{~s}^{-1}$ at $\eta=200 \mathrm{mV}$, and TOFs calculated from experimental surface area are $3.87 \mathrm{~s}^{-1}$ at $\eta=100 \mathrm{mV}$ and $4.11 \mathrm{~s}^{-1}$ at $\eta=200 \mathrm{mV}$. The obtained TOF values represent only an approximation of the real TOFs, as the actual hydrogen binding sites are not exactly identified. However, it is possible to conclude that the intrinsic catalytic activity of the CFCo 0t-c sample is about 10 times higher than the activity of the CFCo 0t-o catalyst. The obtained TOF values proved the beneficial effect of the use of a closed sintering system during the production of the catalyst on its catalytic activity.

\section{Conclusion}

In summary, carbon micro-fibers modified with $\mathrm{Co}_{2} \mathrm{P}$ nanoparticles and decorated by CNTs were prepared by needle-less electrospinning technique. As expected, after optimization of sintering conditions and the structural and compositional metrics, carbon fibers with cobalt phosphides sintered in closed systems exhibited better electrochemical performance for HER than bare carbon fibers or carbon fibers with cobalt phosphides sintered freely. On the other hand, carbon fibers sintered in open system without prolonged exposure time at the $1200{ }^{\circ} \mathrm{C}$ showed better electrochemical activity than the same carbon fibers held in the furnace at high temperature for longer time. More specifically, fibers CFCo 0t-c calcined in the closed system require an overpotential of $-280 \mathrm{mV}$ to afford a current density of $10 \mathrm{~mA} . \mathrm{cm}^{-2}$ with a low Tafel slope of $67.03 \mathrm{mV} \cdot \mathrm{dec}^{-1}$, while the samples CFCo 0t-o calcined in the open system showed the overpotential of $-345.07 \mathrm{mV}$ for the same current density with the Tafel slope of $73.15 \mathrm{mV} \cdot \mathrm{dec}^{-1}$. Both electrodes exhibit excellent stability under operating conditions.

Acknowledgements This work was supported by Slovak Research and Development Agency under the contract no. APVV 20-0229 and Grant Agency of Slovak Academy of Sciences, projects No. VEGA 2/0036/20, VEGA $1 / 0095 / 21$ and SAS Program for PhD students grants no. APP 0088. The support of Slovak Research and Development Agency (contract no. 18-0357) is also gratefully acknowledged.

\section{References}

KH An WS Kim YS Park HJ Jeong YCh Choi Moon JMi, Bae DJ, Lim SCh, Lee1 YH, 2001 Supercapacitors using single-walled carbon nanotube electrodes. Adv Mater. 13497500 https://doi.org/10. $1063 / 1.1420099$

Andrews L, Citra A (2002) Infrared spectra and density functional theory calculations on transition metal nitrosyls, Vibrational frequencies of unsaturated transition metal nitrosyls. Chem Rev 102:885-912. https://doi.org/10.1021/cr0000729

Aykut Y, Pourdeyhimi B, Khan SA (2016) Effects of surfactants on the microstructures of electrospun polyacrylonitrile nanofibers and their carbonized analogs. J Appl Polym Sci 130:3726-3735. https://doi.org/10.1002/app.39637

Bachtold A, Hadley P, Nakanishi T, Dekker C (2001) Logic Circuits with Carbon Nanotube Transistors Science 294:1317-1320. https://doi.org/10.1126/science.1065824

Bonard JM, Chauvin P, Klinke C (2002) Monodisperse multiwall carbon nanotubes obtained with ferritin as catalyst. Nano Lett 2:665-667. https://doi.org/10.1021/n10255606

Chen Y, Ciuparu D, Lim S, Yang Y, Haller GL, Pfefferle L (2004) Synthesis of uniform diameter single-wall carbon nanotubes in Co-MCM-41: effects of the catalyst prereduction and nanotube growth temperatures. J Catal 225:453-465. https://doi.org/10. 1016/j.jcat.2004.04.022

Chen Y, Ciuparu D, Lim S, Yang Y, Haller GL, Pfefferle L (2004b) Synthesis of uniform diameter single wall carbon nanotubes in Co-MCM-41: Effects of CO pressure and reaction time. J Catal 226:351-362. https://doi.org/10.1016/j.jcat.2004.06.006 
Chen Y, Ciuparu D, Lim S, Haller GL, Pfefferle LD (2006) The effect of the cobalt loading on the growth of single wall carbon nanotubes by $\mathrm{CO}$ disproportionation on Co-MCM-41 catalysts. Carbon 44:67-78. https://doi.org/10.1016/j.carbon.2005.07.035

Chen X, Wang D, Wang Z, Zhou P, Wu Z, Jiang F (2014) Molybdenum phosphide: a new highly efficient catalyst for the electrochemical hydrogen evolution reaction. Chem Commun 50:11683-11685. https://doi.org/10.1039/c4cc05936k

Ding B., Wang X., Yu J., Electrospinning (2019): Nanofabrication and Applications, Elsevier

IEA (2020), Global Energy Review 2020, IEA, Paris, The impacts of the Covid-19 crisis on global energy demand and $\mathrm{CO}_{2}$ emissions, 2020. https://www.iea.org/reports/global-energy-review-2020/ renewables.

Garg K, Bowlin GL (2011) Electrospinning Jets and Nanofibrous Structures Biomicrofluidics 5:13403. https://doi.org/10.1063/1. 3567097

Greeley J, Nørskov JK (2005) A general scheme for the estimation of oxygen binding energies on binary transition metal surface alloys. Surf Sci 592:104-111. https://doi.org/10.1016/j.susc.2005.07.018

Heckova M, Streckova M, Orinakova R, Hovancova J, Guboova A, Sopcaka T, Kovalcikova A, Plesingerova B, Medved D, Szabo J, Dusza J (2020) Porous carbon fibers for effective hydrogen evolution. Appl Surf Sci 506:144955. https://doi.org/10.1016/j.apsusc. 2019.144955

Hernadi K, Fonseca A, Nagy JB, Siska A, Kiricsi I (2000) Production of nanotubes by the catalytic decomposition of different carboncontaining compounds. Appl Catal A-General 199:245-255. https://doi.org/10.1016/S0926-860X(99)00561-X

Iijima S (1991) Helical microtubules of graphitic carbon. Nature 354:56-58. https://doi.org/10.1038/354056a0

Inagaki M, Yang Y, Kang F (2012) Carbon nanofibers prepared via electrospinning. Adv Mater 24:2547-2566. https://doi.org/10. 1002/adma.201104940

Jirsak O, Petrik S (2012) Recent Advances in Nanofibre Technology: Needleless Electrospinning Int J Nanotechnol 9:836-845. https:// doi.org/10.1504/IJNT

Johra FT, Lee JW, Jung WG (2017) Facile and safe graphene preparation on solution based platform. J Ind Eng Chem 20:2883-2887. https://doi.org/10.1016/j.jiec.2013.11.022

Kartick B, Srivastava SK, Srivastava I (2013) Green synthesis of graphene. J Nanosci Nanotechnol 13:4320-4324. https://doi.org/10. 1166/jnn.2013.7461

Kibsgaard J, Tsai Ch, Chan K, Benck JD, Nørskov JK, Abild-Pedersen F, Jaramillo TF (2015) Designing an improved transition metal phosphide catalyst for hydrogen evolution using experimental and theoretical trends. Energy Environ Sci 8:3022-3029. https://doi. org/10.1039/C5EE02179K

Kong D, Cha JJ, Wang H, Lee HR, Cui Y (2013) First-row transition metal dichalcogenide catalysts for hydrogen evolution reaction. Energy Environ Sci 6:3553-3558. https://doi.org/10.1039/C3EE4 $2413 \mathrm{H}$

Kumar M, Ando Y (2010) Carbon Nanotube Synthesis and Growth Mechanism. Nanotechnology Perception 6:7-28. https://doi.org/ $10.5772 / 19331$

Liserre M, Sauter T, Hung JY (2010) Future energy systems: Integrating renewable energy sources into the smart power grid through industrial electronics. IEEE Ind Electron Mag 4:18-37. https:// doi.org/10.1109/MIE.2010.935861

Lyu SC, Liu BCh, Lee SH, Park ChY, Kang HK, Yang ChW, Lee ChJ (2004) Large-scale synthesis of high-quality double-walled carbon nanotubes by catalytic decomposition of $\mathrm{n}-\mathrm{Hexane}$. J Phys Chem B 108:2192-2194. https://doi.org/10.1021/jp030955e
Mo YH, Kibria AKM, Nahm KS (2001) The growth mechanism of carbon nanotubes from thermal cracking of acetylene over nickel catalyst supported on alumina. Synth Met 122:443-447. https:// doi.org/10.1016/S0379-6779(00)00565-8

Niu H, Zhou H, Wang H (2019), Electrospinning: an advanced nanofiber production technology electrospinning: an advanced nanofiber production technology. In: Energy harvesting properties of electrospun nanofibers. IOP Publishing. 1-44

Nørskov JK, Bligaard T, Logadottir A, Kitchin JR, Chen JG, Pandelov S, Stimming U (2005) Trends in the Exchange Current for Hydrogen Evolution. J Electrochem Soc 152:J23-J26. https://doi.org/ $10.1149 / 1.1856988$

M Pérez-Cabero, E Romeo, C Royo, A Monzón, Guerrero-Rúz A, Rodŕíguez-Ramos I, 2004. Growing mechanism of CNTs: a kinetic approach. J Catal. 224197 205. https://doi.org/10.1016/j. jcat.2004.03.003

Rahaman MSA, Ismail AF, Mustafa A (2007) A review of heat treatment on polyacrylonitrile fiber. Polym Degrad Stab 92:14211432. https://doi.org/10.1016/j.polymdegradstab.2007.03.023

Shi Y, Zhang B (2016) Recent advances in transition metal phosphide nanomaterials: synthesis and applications in hydrogen evolution reaction. Chem Soc Rev 45:1529-1541. https://doi.org/10.1039/ c5cs00434a

Stigka EK, Paravantis JA, Mihalakakou GK (2014) Social acceptance of renewable energy sources: a review of contingent valuation applications. Renew Sustain Energy Rev 32:100-106. https://doi. org/10.1016/j.rser.2013.12.026

Streckova M, Mudra E, Orinakova R, Markusova-Buckova L, Sebek M, Kovalcikova A, Sopcak T, Girman V, Dankova Z, Micusik M, Dusza J (2016) Nickel and nickel phosphide nanoparticles embedded in electrospun carbon fibers as favourable electrocatalysts for hydrogen evolution. Chem Eng J 303:167-181. https://doi.org/10. 1016/j.cej.2016.05.147

Streckova M, Orinakova R, Mudra E, Dankova Z, Sabalova M, Girman V, Kovalcikova A, Hovancova J, Heckova M, Kalavsky F, Dusza J (2018) Design of electroactive carbon fibers decorated with metal and metal-phosphide nanoparticles for hydrogen evolution technology. Energy Technol 6(1310):1331. https://doi.org/10.1002/ ente. 201700879

Streckova M, Orinakova R, Hovancova J, Heckova M, Guboova A, Girmana V, Mudra E, Dankova Z, Bekenyiova A, Dusza J (2020) Novel electrocatalysts for hydrogen evolution based on carbon fibers modified by cobalt phosphides. Appl Surf Sci 507:144927. https://doi.org/10.1016/j.apsusc.2019

Vinciguerra V, Buonocore F, Panzera G, Occhipinti L (2003) Growth mechanisms in chemical vapour deposited carbon nanotubes. Nanotechnology 14:655-660. https://doi.org/10.1088/0957-4484/ $14 / 6 / 317$

Wang LL, Johnson DD (2009) Predicted Trends of Core-Shell Preferences for 132 Late Transition-Metal Binary-Alloy Nanoparticles. J Am Chem Soc 131:14023-14029. https://doi.org/10.1021/ja903 $247 x$

Wei BQ, Vajtai R, Jung Y, Ward J, Zhang R, Ramanath G, Ajayan PM (2003) Assembly of highly organized carbon nanotube architectures by chemical vapor deposition. Chem Mater 15:1598-1606. https://doi.org/10.1021/cm0202815

Xiang X, Zhang L, Hima HI, Li F, Evans DG (2009) Co-based catalysts from $\mathrm{Co} / \mathrm{Fe} / \mathrm{Al}$ layered double hydroxides for preparation of carbon nanotubes. App Clay Sci 42:405-409. https://doi.org/10. 1016/j.clay.2008.04.004

Yalcinkaya F, Yalcinkaya B, Jirsak O (2016) Dependent and Independent Parameters of Needleless Electrospinning. Electrospinning 
- Material, Techniques, and Biomedical Applications, Sajjad Haider and Adnan Haider, IntechOpen. https://doi.org/10.5772/ 65838

Yuan L, Li T, Saito K (2003) Growth mechanism of carbon nanotubes in methane diffusion flames. Carbon 41:1889-1896. https://doi. org/10.1016/S0008-6223(03)00204-5

Zanello LP, Zhao B, Hu H, Haddon RC (2006) Bone Cell Proliferation on Carbon Nanotubes. Nano Lett 6:562-567. https://doi.org/10. $1021 / \mathrm{nl} 051861 \mathrm{e}$

Zeng M, Li Y (2015) Recent advances in heterogeneous electrocatalysts for the hydrogen evolution reaction. J Mater Chem A 3:14942-14962. https://doi.org/10.1039/c5ta02974k

Zhang W, Hu Y, Ma L, Zhu G, Wang Y, Xue X, Chen R, Yang S, Jin Z (2018) Progress and Perspective of Electrocatalytic $\mathrm{CO}_{2}$ Reduction for Renewable Carbonaceous Fuels and Chemicals. Adv Sci 5: 1700275. https://doi.org/10.1002/advs.201700275
Zhao N, He C, Jiang Z, Li J, Li Y (2006) Fabrication and growth mechanism of carbon nanotubes by catalytic chemical vapor deposition. Mater Lett 60:159-163. https://doi.org/10.1016/j.matlet. 2005.08.009

Zhou W, Jia J, Lu J, Yang L, Hou D, Li G, Chen Sh (2016) Recent developments of carbon-based electrocatalysts for hydrogen evolution reaction. Nano Energy 28:29-43. https://doi.org/10.1016/j. nanoen.2016.08.027

Zhu HW, Xu CL, Wu DH, Wei BQ, Vajtai R, Ajayan PM (2002) Direct synthesis of long single-walled carbon nanotube strands. Science 296:884-886. https://doi.org/10.1126/science.1066996

Publisher's Note Springer Nature remains neutral with regard to jurisdictional claims in published maps and institutional affiliations. 